IUCrJ

ISSN 2052-2525

BIOLOGY|MEDICINE

Keywords: protein crystals; crystal lattices

\section{Comment on the article 'Protein crystal lattices are dynamic assemblies: the role of conformational entropy in the protein condensed phase'}

\author{
Massimo Nespolo* \\ CNRS, CRM2, Université de Lorraine, Nancy, F-54000, France. *Correspondence e-mail: \\ massimo.nespolo@univ-lorraine.fr
}

In a recent article by Dimova \& Devedjiev (2018), the word 'lattice' occurs 32 times, and the term 'crystal lattice' 23 times. Actually, none of these occurrences concern the lattice but the structure. The distinction is of paramount importance because a lattice is an abstract mathematical concept that expresses the periodicity of the atomic distribution in the crystal space; the latter is the crystal structure. The confusion between these two fundamental concepts may lead to serious misunderstandings, like the term 'polar lattice' (page 136). A lattice being always centrosymmetric (in an odd-dimensional space), it can never be polar, whereas the crystal structure can. Furthermore, the term 'polar lattice' is used to indicate a completely different concept: the ancestor of the reciprocal lattice (Nespolo \& Souvignier, 2010).

\section{References}

Dimova, M. \& Devedjiev, Y. D. (2018). IUCrJ, 5, 130-140.

Nespolo, M. \& Souvignier, B. (2010). J. Appl. Cryst. 43, 1144-1149.

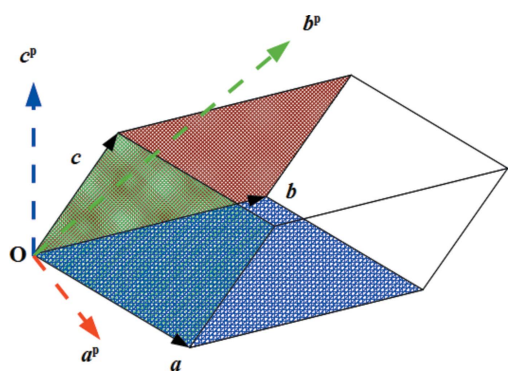

OPEN $\odot$ ACCESS 
IUCrJ

ISSN 2052-2525

BIOLOGY|MEDICINE

Keywords: protein crystals; crystal lattices

\section{Response to comment on 'Protein crystal lattices are dynamic assemblies: the role of conformational entropy in the protein condensed phase'}

\author{
Margarita Dimova and Yancho D. Devedjiev* \\ Department of Anesthesiology, University of Virginia, 1215 Lee Street, Charlottesville, VA 22908, USA. *Correspondence \\ e-mail: idd3cgm@gmail.com
}

Nespolo (2018) analyses our paper (Dimova \& Devedjiev, 2018) from the point of view of crystallography that studies the asymmetric unit of the crystals. From this point of view, the crystal lattice is indeed a mathematical abstraction - a three-dimensional array of identical units. We analyze protein crystals as physical objects and demonstrate that the units in the crystal may not be identical in the same volume and at the same time. To the best of our knowledge this is a new concept that has not been proposed before.

\section{References}

Dimova, M. \& Devedjiev, Y. D. (2018). IUCrJ, 5, 130-140.

Nespolo, M. (2018). IUCrJ, 5, https://doi.org/10.1107/S2052252518006267.

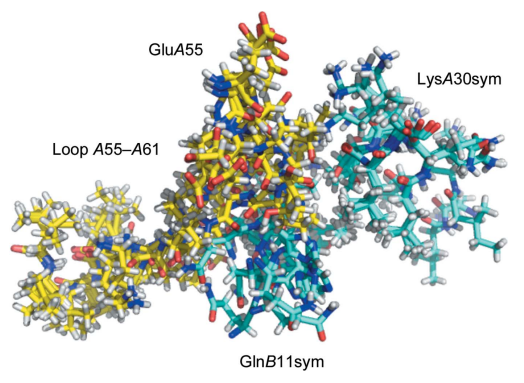

OPEN $\odot$ ACCESS 